\title{
Possible Mesoamerican Naked-eye Observation of Sunspots - V: Evidence from Río Azul Tomb I Murals and Related Artifacts
}

\author{
Richard R. Zito \\ Summerhaven Observatory, P.O. Box 663, Mt. Lemmon, AZ 85619, USA
}

Copyright $\mathrm{O} 2016$ by authors, all rights reserved. Authors agree that this article remains permanently open access under the terms of the Creative Commons Attribution License 4.0 International License

\begin{abstract}
Many cultures of antiquity have made naked-eye observations of large sunspot displays. The Chinese, Japanese, Koreans, and Greeks, have all made such observations. Pictorial evidence on dated Mesoamerican monuments suggests that similar observations may have been made in the New World as well. In this regard, Tomb 1 at Río Azul is of particular interest. Within the tomb, murals depict a spotted Sun God as the "father" of Tikal king "Curl Snout" (Yax Nuun Ayiin I). Therefore, the murals of Tomb 1 corroborate the information gleaned from Stela 31. However, the iconography at Río Azul is more explicit, with the Sun God displaying two Kin signs on his head. As in the previous report on Stela 31, the spotted Sun God is probably a reference to the naked eye sunspot series terminating in 400 $\mathrm{AD}$ that presaged the end of Curl Snout's life in $404 \mathrm{AD}$.
\end{abstract}

Keywords Maya, Río Azul, Murals, Sun God, Sunspots

\section{Background: The Larger Context}

Our Sun is a variable star, with active and quiet periods marked by the presence and absence of sunspots. Everyone is aware of the 11-year sunspot cycle, but other solar sunspot cycles also exist with periods that may last 500 or even 2000 years. And, there is no reason why longer solar cycles cannot exist that is presently unknown. The shorter cycles are better understood because telescopic sunspot counts have been recorded ever since Galileo first turned his telescope toward the Sun in 1610. The longer cycles and their duration are less well understood because astronomers and astrophysicists have no scientific records going back far enough in time. It must always be realized that the time interval from 1610 to the present is only about 400 years, not even the duration of a single 500 year cycle. Worse still, 400 years represents a little less than one ten millionth of the Sun's present $4.55 \pm$ 0.1 billion year age! Consequently, scholars must rely on historical eye witness reports of outstanding naked-eye events to judge solar activity levels during the longer cycles.
Reports from Far East Asia (China, Japan, and Korea) [1] have been particularly useful in this regard because these ancient cultures had astronomical traditions and a written language so that we can be reasonably sure that what they were describing were, in fact, sunspots. Also, these cultures had a numerical system and a calendar. Therefore, their observations can be securely correlated with the modern Gregorian calendar and dated. However, there are problems. First, there appear to be gaps in the historical record, and it is uncertain whether these gaps are real or simply reflect a lack of interest in making such observations. Second, the observations don't go back in time as long as astronomers would like. Even a record going back 4000 years represents only two 2000 year cycles, and about one millionth of the Sun's age. One millionth of the Sun's total activity history might not sound like much, but for a physicist, it is a veritable gold mine of data. There is also a third problem. The written descriptions accompanying some of the ancient observations have led some scholars to believe that a few of the "sunspot" observations were actually phenomena within the Earth's atmosphere. These, of course, should be purged from the record if it could be verified that they were not solar events. In short, it would be very helpful for solar modeling if other sunspot records existed, independent of the Far Eastern observations cited above. This especially true for records older than 2000 years BP, which are very sparse. In this regard, there are many astronomical traditions to choose from $[2,3,4,5]$.

Records from the Indian subcontinent also seem promising [2,3,5]. And, there has been found a very suggestive legend in Indian folklore. According to the Sthalamparana, the official history of the Surnarkoil temple in southern India near the town of Mayiladuthurai, the Sun had become infected with leprosy [6]! This may be a reference to sunspots in terms of what the people of that time and place were familiar with. Dating such an astonishing statement is difficult, but a first step might be to establish a lower bound (age-wise) by accelerator dating the Sthalamparana. Although, the myth itself may be a lot older. A milligram of material from an unimportant location in the 
manuscript would be enough of a sample for a firm date. This example shows that there may be information on sunspots to be collected from India. And, some of that information may be very old. However, there are problems. The most ancient Indian script from the Indus Valley Civilization (c. 2500 BC) is still undeciphered [7]. Nevertheless, Kharosthi, Brahmi, Sanskrit and many of their more than 200 younger derivative scripts are well understood. The real question is, as with so many ancient civilizations, "Have scholars, literate in these scripts, looked thoroughly for sunspot information in this vast data base?"

In the Middle East, people had invented writing, a numerical system, and a calendar. Therefore, such records can potentially provide accurate scientific data about ancient astronomical events for modern scholars. The Sumerians left written religious records about the Sun God and Moon Goddess. While Babylonian and Assyrian priests recorded the motions of the Sun, Moon, planets, and stars for astrologic purposes. By 500 BC Babylonian astrologers could accurately predict eclipses. Even older Babylonian Venus observations (1200 BC) were recorded in the seventh century BC by the Assyrians. And, what is more important for this study, there exists a 3,000 year-old Babylonian tablet that seems to contain a reference to sunspot observations $[8,9]$. However, only the Greeks, if Greece can be grouped with the Middle East as far as their astronomical traditions are concerned, seem to have left clear sunspot references [10]. It should also be noted that there are several ancient Middle Eastern scripts that remain at least partially undeciphered. These include Proto-Elamite (c. 3000 BC) from Iraq and Iran, Pseudo-Hieroglyphic from Lebanon, and Linear A (1800 BC) from Crete [7]. It may be that fundamental breakthroughs in our understanding of these ancient scripts is required before historical sunspot research for these cultures can progress. Nevertheless, there is certainly very valuable information to be mined from Egyptian/Arabic/Islamic sources. The Nilometer records [11] that measure the height of the Nile waters are particularly useful because this data series, that starts in pharaonic times and extends into modern times via Islamic scholarship, is one of those terrestrial data sets that is approximately phase locked to solar activity. It is also one of the longest data series known. And, those two facts make Nilometer data a very useful tool for estimating solar activity levels in a general way. Some of this Nilometer data has already been used in the second publication of this series on Mayan sunspot observations [12] to correlate the active Sun with the presence of the spotted Sun God in the Dresden Codex. Unfortunately, the author's work on Nile levels at the (pharaonic) Luxor quay was interrupted by the recent political turmoil in Egypt. It is natural to ask if any direct solar observations exit. In the case of pharaonic Egypt, the restrictions placed on art by tradition seem to have erased a lot of valuable data. Certainly, some non-standard solar images exist. For example, the apparent oblateness of the rising Sun due to atmospheric effects is depicted in Egyptian art [13]. The solar disk is particularly easy to observe at sunrise and sunset over the Sahara due to suspended dust particles, and the ancient Egyptians certainly did observe [14]. However, a decision on sunspots is still pending. Although, some tempting, but inconclusive, art work exists. Examination by the author of Islamic artifacts in the collections of the Metropolitan Museum of Art (New York), the Brooklyn Museum of Art (Brooklyn), the Louvre (Paris), the Institut du Monde Arabe (Paris), the Benaki Museum of Islamic Art (Athens), and the National Museum (New Delhi), has not revealed any obvious pre-telescopic information on sunspots. Available translated astronomical Islamic literature contains the usual fare of architectural alignments [15], eclipses, planetary conjunctions [16], etc., but nothing on sunspots was found. Thurston [3] is of the opinion that the main importance of Islamic astronomy lies in "(i) the preservation of Ptolemy's work; (ii) the improved theory of the moon; and (iii) accurate determination of parameters". However, it must always be remembered that "unfortunately today even some of the most basic works... have been only partially studied, not to speak of many which remain forgotten in manuscript form in various libraries", so that "almost every day there are still important and major discoveries made in this field" [17]. Islamic astronomical handbooks alone (the zijes), compiled by Muslim astronomers during the millennium following the rise of Islamic astronomy in the eighth century, number almost 200. These contain extensive tables and instructions for solving the standard problems confronting medieval astronomers, such as the determination of planetary and stellar positions, the computation of conjunctions and eclipses, and problems relating to timekeeping [16]. In addition to a lack of scholarly penetration, there is outright loss of materials. In the $11^{\text {th }}$ century Ibn al-Sanbadi had counted 6,500 manuscripts relating to astronomy, mathematics, and philosophy in the Cairo library. Not one of these survives among the 2,500 scientific manuscripts preserved in Cairo today [18]. However, it is worth noting that Ibn Yünus recounts that the Banū Amājūr family (original zij lost) observed the eclipse of 928 in Baghdad by looking at the reflection of the Sun in water [18]. Such a technique would have reduced the glare of the Sun and revealed naked-eye sunspots, during the partial phases before and after totality, had there been any to observe. And, south of the Arab world, there is an African myth from Zambesi that may be recited as follows: "The Moon envies the Sun and throws mud at its face. Luckily, this does not happen very often since the Sun is vigilant. But, every ten years, approximately, the Sun loses concentration and gets dirtied by the mud." [8]. It is uncertain if the origin of this African myth is indigenous or if it was assimilated from folkloric traditions that diffused south from the Maghreb. Dating such a myth is also problematic. Until scholars examine Islamic literature on astronomy more thoroughly, it will be impossible to know for certain if any direct sunspot observations had been made.

European cave art is very ancient indeed, and dates from about 30,000 to $10,000 \mathrm{BC}$ [19], an age representing almost one 100,000 th, or one thousandth of a percent, of the Sun's age. The interpretation of such imagery is controversial. And, although it may seem impossible to glean any useful 
information from such material, the task may not be completely hopeless. And, the payoff would be very high! If, for example, a panel shows a solar disk with a spot deliberately carved or painted on it. And, if this panel has other astronomical events on it that are very characteristic, it may be possible to accurately date the panel, provided it can be established that all these images were created at about the same time (either through C-14 measurements on soot or paint fragments, patina analysis, or some other method). It may also be possible to analyze rock art in a similar way. The depiction of constellations as they were perhaps tens of thousands of years ago may allow dating via the known proper motion (i.e. actual motion in space [19]) of various stars (especially high velocity "flying stars" [20]). Consequently, the catalogues of Eurasian rock art containing astronomical motifs, like that compiled by N.M. Bekbassar for Central Asia [21], may be of incalculable value. Whether the data harvested from such investigations is accurate enough to be useful is another question. Megalithic astronomical traditions from Western Europe date from 7,000 years BP [22]. Certainly, many astronomical alignments of Megalithic structures are known. However, in this time before writing, the researcher must again rely on the interpretation of art for information on sunspots. In particular, the solar bronze "shield" found at Dolmenes de Antequera in Spain is very suggestive and deserves high resolution inspection and photography of its surface [23]. In medieval times, there are reports of sunspots, solar prominences, and aurora from Russia [24,25]. European records of aurora [26] provide precise information on solar activity that can be used to corroborate observations from Far East Asia. Many of these records go all the way back to ancient Rome [27].

Finally, there is information from Mesoamerica. The Maya have a long astronomical tradition (especially solar observation), invented writing, a numerical system, and a calendar (all deciphered). These facts, together with the close proximity of the southwestern U.S. (the author's location) to Mayan archaeological sites, and the great store of Mayan artifacts in American museums, makes the Maya a prime target for acquisition of sunspot data. The very first suggestion that the Maya may have observed sunspots came from Galindo Trejo and Allen in 2005 [28]. The Fresco Hall, at the southern end of the Central Plaza of the Post-Classic Mayapan ruins, shows descending personages inside Sun circles of various panels. Trejo and Allen suggested that this might represent a Venus transit, or a naked-eye sunspot interpreted as Venus inside the solar disk by Mayan priest/astronomers. It should also be noted that, in addition to the Maya, other Mesoamerican people may be a source of sunspot information as well. For example, there is a pre-Columbian Aztec myth that has a Sun God with "dirty marks" on his face $[8,29]$. However, some Olmec data may remain out of reach until larger samples of the La Mojarra script (Epi-Olmec script from Veracruz, Mexico; c. 150 AD) are found $[7,30]$. Data may also be available from rock art in the southwestern U.S. since the Anasazi (including the Chaco Canyon culture) are known to have had contact (direct or indirect) with Mesoamerica, as judged from trade items found in ruins (e.g. tropical bird feathers) [31]. The same is true for the Sinagua who interacted with cultures to the south in Mexico through the intermediary of the Hohokam culture. These interactions are known because of the similar ball court architecture found at the ruins of these ancient people of the American southwest.

In this summary of ancient sunspot observations and related material, the emphasis has been placed on parts of the globe that, in the author's opinion, might be considered the most accessible and promising information sources (but, certainly not the only sources) with the largest potential payoff for sunspot studies. The cultures surveyed might be broken up into four groups. In Group I are cultures that have systematically recorded sunspots over a long period of time. These are the Far Eastern cultures; China, Japan, and Korea. Next, come Group II cultures that have occasionally (at least once) observed sunspots, but no systematic records are currently known to exist. These include the Indian, Babylonian, Greek, medieval European, African, Mayan and Aztec cultures discussed above. Group III comprise traditions for which no evidence of direct sunspot observation is currently known, but have produced indirect evidence of solar activity (e.g. Nilometer records, auroral sightings). These include ancient Egyptian, Islamic, and Roman traditions. Finally, Group IV is comprised of those cultures for which no solar activity related information is currently known to exist. This group contains Sumerian, Assyrian, and Megalithic European traditions, as well as the Olmec, Anasazi, Sinagua, and Hohokam cultures of the New World. The goal of this Mayan series on sunspots as stated in the Abstract may now be restated in more technical terms. It will be the goal of this series of publications to move the Maya from group II to Group I, and to apply this new data series to the solution of certain astrophysical problems related to the long-term behavior of the Sun. Furthermore, It is hoped that this background section puts the Mayan observations in their proper context with respect to other astronomical traditions and, perhaps, points out a few ways forward for future research in this vast area of scholarship that will undoubtedly require many lifetimes of careful analysis to complete.

\section{Background to Mayan Astronomical Observations}

The Sun God of the Mayan pantheon is often depicted with three facial spots on his cheek forming a small equilateral triangle. At other times the spots are absent. There are three theories about this curiosity. Fialco [32] has suggested that the spotted Sun God is an emblematic device of the Tikal dynasty. However, the spotted Sun God is well known from sites and dynasties not connected with Tikal or its rulers [33,34]. Two other suggestions were made by Milbrath [34]. Perhaps the Sun God's facial markings are death spots or jaguar spots. Neither of these hypotheses has proven completely acceptable either because the Sun God is 
associated with growth (especially of life-giving corn) and the jaguar is a night animal. However, there is a fourth possibility. Perhaps the artistic device of the spotted Sun God is simply a direct reflection of observed solar activity by Mayan priest/astronomers; although no direct evidence, such as a table of naked-eye sunspot observations, is known to exist [34,35]. Since Mayan political and mythological material is often dated, it becomes possible to correlate the presence of the spotted Sun God with the actual physical condition of the Sun as evidenced by Far East Asian sunspot observations and physical data. The first four papers of this series on Mayan sunspot observations demonstrate a positive correlation [12,33,36,37]. That is to say, the presence of a spotted Sun God is indicative of high solar activity, while the absence if cheek spots are indicative of a quiet Sun. This then establishes an "if and only if" relationship between the iconography and solar activity. The selection of Mayan artifacts for study has been dictated by four rules [12].

1) The artistic motif must be present (Sun God with or without spots)

2) The artifact upon which the image occurs must be dated or dateable.

3) Solar activity levels must be verifiable by direct observation from some ancient culture.

4) Observations must be substantiated by scientific data (i.e. tree ring analysis, Nilometer Measurements, auroral activity, carbon-14 measurements, etc.)

Taken together, this is a difficult set of criteria to satisfy. So, the number of artifacts that is capable of analysis is necessarily limited. In this paper only three artifacts will be analyzed, all from Río Azul and its neighborhood.

\section{The Site - Río Azul Tomb 1 and Its Murals}

The city state of Río Azul, on the river of that name in Guatemala, lies near the corner where Mexico, Guatemala, and Belize meet (called the Three Rivers Region $-89^{\circ} 14^{\prime} \mathrm{W}$. longitude, $17^{0} 47^{\prime}$ N. latitude in UTM zone 16Q) (Figure 1A).
It was a thriving city of 729 buildings that was first settled in about $2000 \mathrm{BC}$, it reached its zenith during the Mayan Classic Period, and declined about 900 AD. This report is concerned with the Early Classic murals in Tomb 1, under temple C-1 in the northeastern quadrant of Río Azul (Figure 1B) [1]. The tomb itself probably dates from circa $460 \mathrm{AD}$. The occupant of the tomb was a man provisionally named Governor $\mathrm{X}$ because of uncertainty concerning the interpretation of his name glyph. The glyphs in Governor X's tomb state that he was born on the equivalent Gregorian date of September 29, $417 \mathrm{AD}$, and the right side of the rear eastern wall summarizes the Governor's lineage from the Sun God as follows: Sun God $\rightarrow$ Curl Snout (Yax Nuun Ayiin $I) \rightarrow$ Stormy Sky (Siyaj Chan K'awiil II) $\rightarrow$ Governor X (Figure 2). That is to say, Governor $\mathrm{X}$ was probably a younger son of Stormy Sky of Tikal and, although not an heir to the powerful Tikal throne, was nevertheless sent out to rule a vassal city state like Río Azul [38]. Most importantly, from the stand point of this publication, is the fact that the mural's Sun God has the characteristic 3 cheek spots associated with an active Sun that displays naked-eye sunspots. The spotted Sun God is depicted as the "father" of Curl Snout, whose dates are 379 to $\sim 404$ AD. As previously discussed in the fourth paper of this series on Tikal Stela-31 [37], a long series of outstanding naked eye sunspots presaged Curl Snouts accession to the throne by 4 years, and four other massive naked eye sunspot events occurred during his life, with the final event presaging his death by about 4 years again. This remarkable coincidence of events tied the spotted Sun God to Curl Snouts life in a way that, mythologically speaking, made the spotted Sun God his "father." In a sense, the Murals of Río Azul provide no new information over and above what is known from Stela 31. However, the Sun God imagery of the lineage at Río Azul is much more explicit, and easier to understand, since a Kin (Sun) sign is tattooed onto the top and back of the Sun God's head. In that sense, the murals offer a useful check on the interpretation of the information found on Stela 31 .

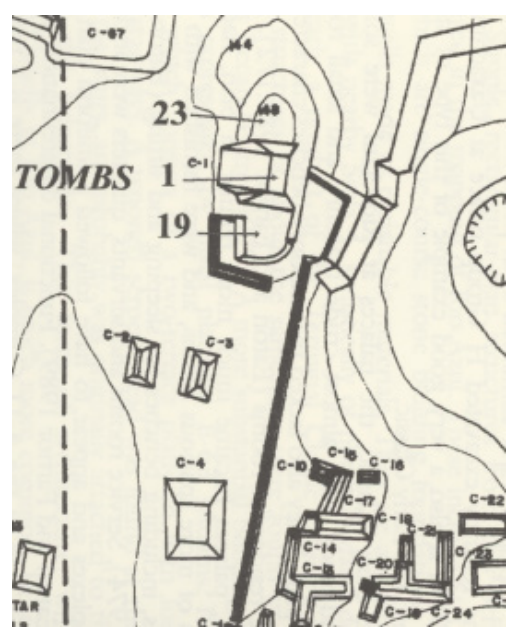

B)

A)

Figure 1. A) The Río Azul region [38]. B) The northeast quadrant of the Río Azul site [38]. (Plan by R.E.W. Adams) 


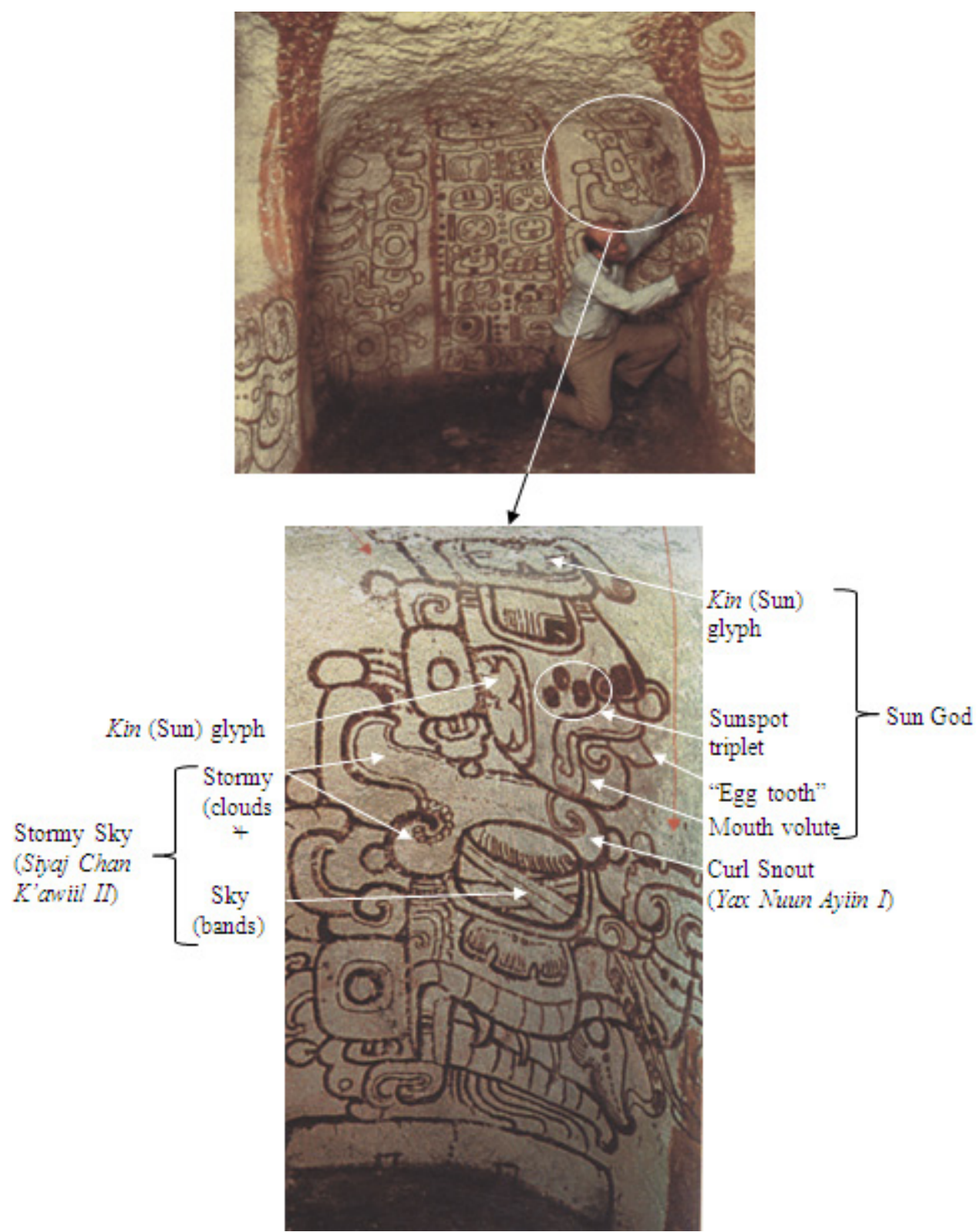

Figure 2. A) The rear (eastern) wall of Tomb 1 showing a triplet of panels [38]. B) Close-up of the right panel [38]. The lineage is Sun God $\rightarrow$ Curl Snout $\rightarrow$ Stormy Sky $\rightarrow$ Governor X (the deceased). It should be noted that the "provisional names" of kings come directly from the literal appearance of king's name glyphs and may not be the king's true name. Linguists have learned how to better read true names in recent years. The facial features that define the Sun God have been marked in B. (Photos by R.E.W. Adams)

\section{Fragment $A$ and the Yucatán Vase}

It is natural to ask if any other Sun God images exist at Río Azul. In this regard, it is of interest to note that two fragments (called A and B) of a carved wooden bowl were found in a looters' camp at Río Azul. It is believed that these fragments came from Tomb 1 based on similarities between the bowl motif and that of the murals of the tomb. The bowl was probably the property of the tomb owner. In that case it must have been created in the 417-460 AD time interval; a period of the quiet Sun. Fragment A shows the large figure of a Collared Peccary [38] (Figure 3A), as evidenced from the cleverly rendered collar. Tayassu Tajacu (collared peccary), Figure 3B, is one of only two species of New World wild pig whose range extends from the southwestern U.S. in the north down to the Río Plata in South America [39]. A Kin (Sun) sign is tattooed onto the top of his head as if he was the Sun God. Furthermore, the cheeks of the peccary have no spots. The meaning of this symbolism may be as follows. The Mayan constellation of the peccary (copulating pair of peccaries) is associated with the modern constellation of Gemini (Figure 4) and lies on the ecliptic (i.e. the yearly path of the Sun's center across the celestial sphere [sky]) [20]. The solar eclipse of April 27, 450 AD [40] in Central America was total at Río Azul (figure 5), and would have occurred when the Sun was about $75^{\circ}$ of right ascension away from Gemini. This constellation's brightest stars Castor and Pollux ( $\alpha$ and $\beta$ Gemini at magnitudes 1.58 and 
1.15 respectively [41]) would have been visible during totality at approximately 1:54 PM local time, since they would be located in that dark part of the sky between the solar corona and the bright horizon that seems to surround an observer during totality [42]. That is to say, there would have been a sky union between the Sun God and the peccary, hence the iconography of Fragment A. The fact that the Sun was quiescent during the $5^{\text {th }}$ century may be why the cheeks of the peccary lack the familiar triangular formation of spots usually associated with solar iconography during periods of high solar activity.

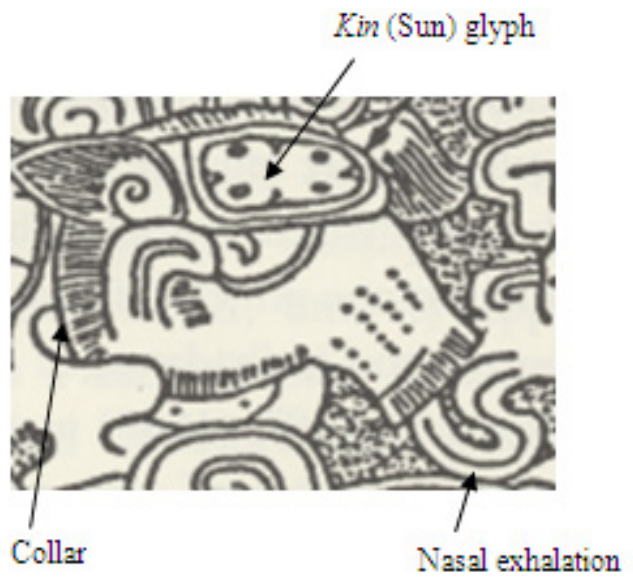

A)

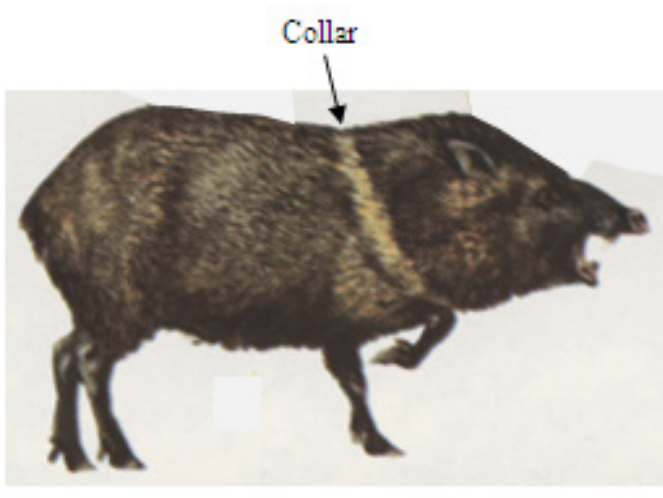

B)

Figure 3. A) Collared Peccary depicted on Fragment A [38]. (Drawing by George E. Stewart) B) Wild Collared peccary (Tayassu Tajacu) [39]. (Animal painting by R. Zieger)

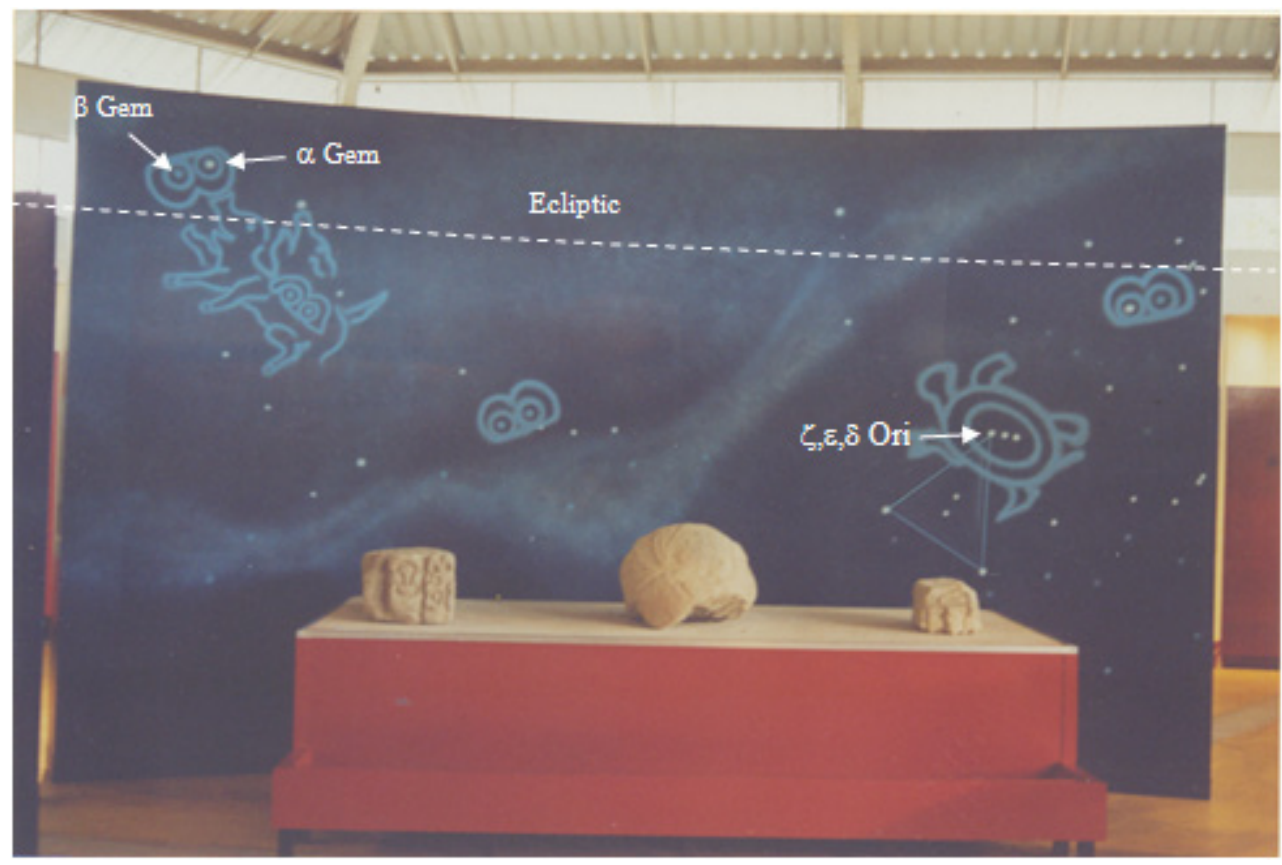

Figure 4. Mural in the Museo de Arqueologia Maya in Copán Ruinas. The Mayan constellation of the two copulating peccaries is seen on the left and corresponds to the standard astronomical constellation of Gemini (Gem). The Mayan constellation of the turtle (right) corresponds to the standard astronomical constellation of Orion (Ori). Key stars and the ecliptic have been added to the mural. 


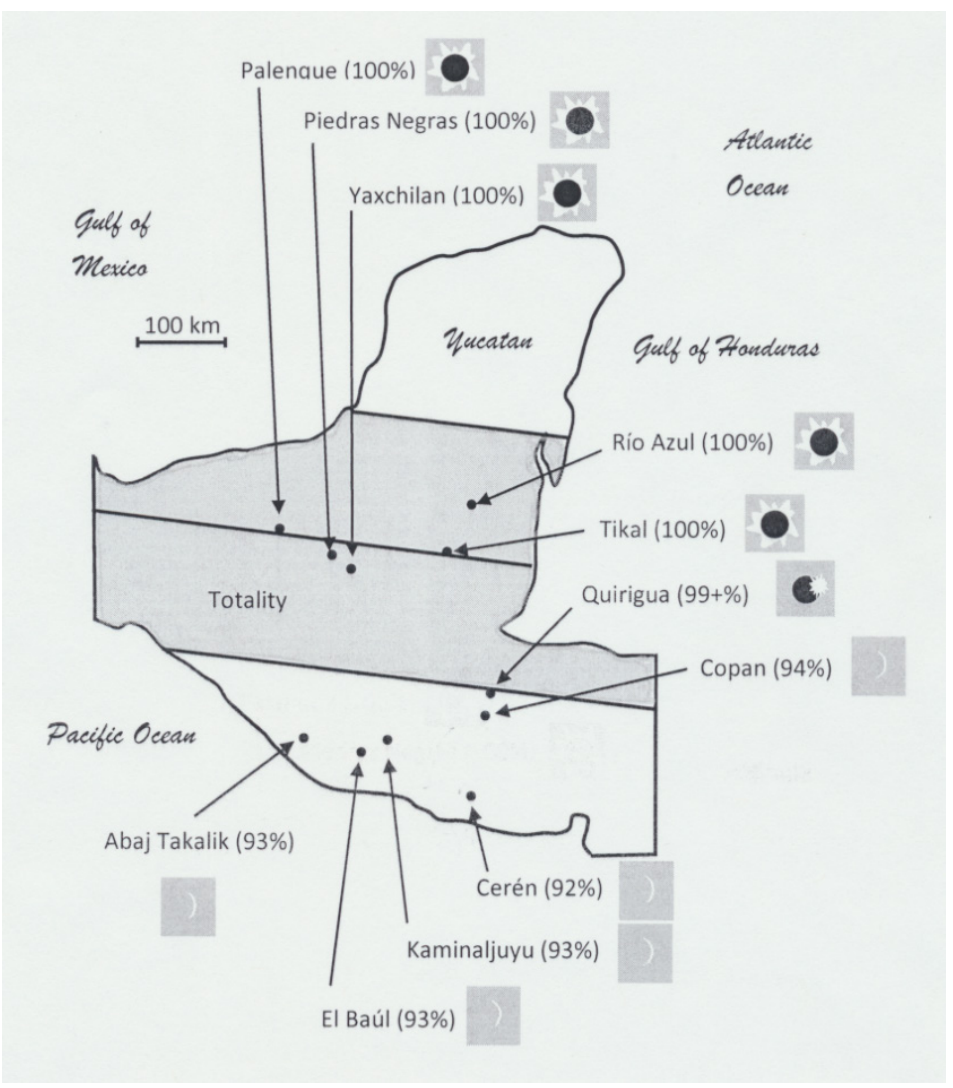

Figure 5. The solar eclipse of April 27, 450 AD as it appeared across the Mayan cultural zone at approximately 1:54 PM local time.

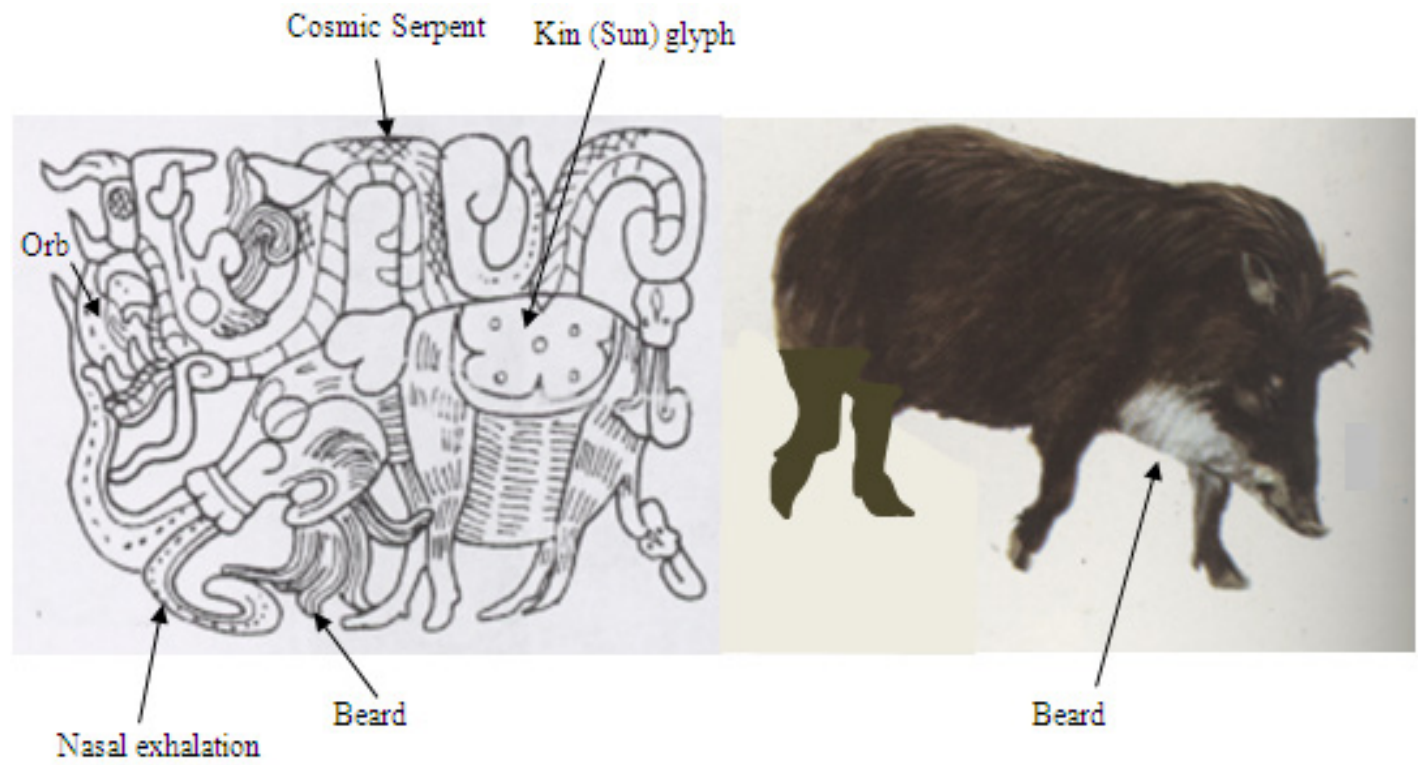

A)

B)

Figure 6. A) The White Lipped Peccary on the Yucatán vase [43, 44]. B) Wild White Lipped peccary (Tayassu ailbirostris) [39]. (Animal painting by R. Zieger, modified by R. Zito) 
Gregorian Year(A.D.)

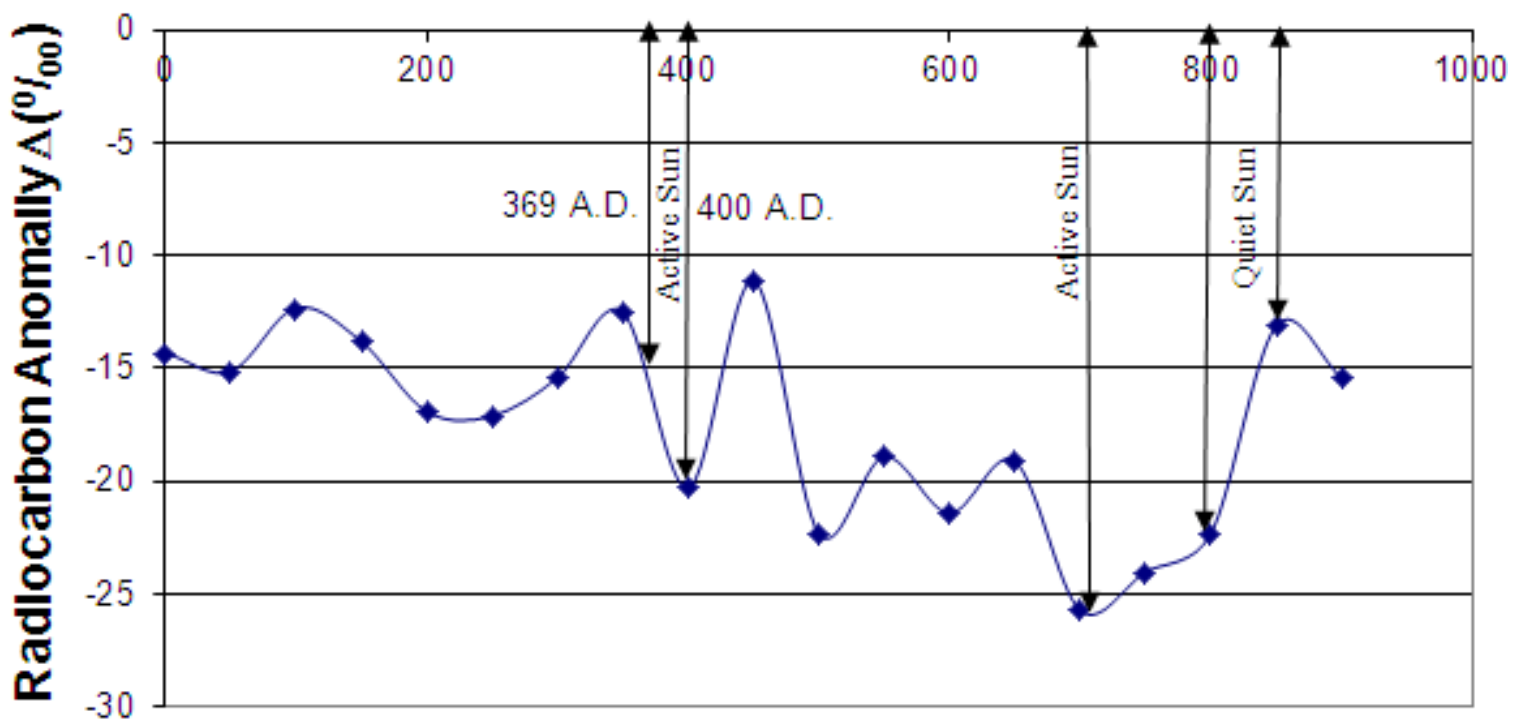

Figure 7. The carbon-14 anomaly as a function of time [37]. (Graph by R. Zito, modified by R. Zito) A peak in solar activity occurred around 369 AD as evidenced by Chinese records and a local minimum in the radiocarbon anomaly 31 years later. Another peak in solar activity should have occurred around $700 \mathrm{AD}$, but no supporting Asian records exist. Finally, $800 \mathrm{AD}$ was a time of the quiet Sun as evidenced by a local maximum in the radiocarbon anomaly about 50 years later. Only local maxima and minima are important for the analysis of solar activity. Average slow, smooth, long-term trends in $\Delta$ over the millennium are due to non-solar activity phenomena like changes in the Earth's magnetic dipole moment and precession of the Earth's axis of rotation.

There is support for the above interpretation of the iconography of Fragment A from other sources. For example, the Gemini-Peccary on a carved vase catalogued by M.D. Coe [43]. The background of the vase images are intaglio (cut-away) so that the top surface of the figures are flush with the original vase surface. The vase came from a private collection in New York, its provenance is thought to be the Yucatán, and it has been stylistically dated to the Late Classic Period (600-900 AD). Nothing more precise is known about this piece because, unfortunately, it had been separated from its archeological context. The vase shows a White Lipped Peccary [44] (Figure 6A), as evidenced by the stylized "beard" under its chin and the absence of a distinctive collar. Tayassu ailbirostris (White Lipped Peccary), Figure $6 \mathrm{~B}$, is the only other New World wild pig, and has a range extending from Campeche Yucatán Mexico in the north, down to the Río Plata in South America [39]. Given the range of this animal, a Yucatán provenance for the vase is consistent, where as an origin of the vase even slightly to the northwest would be unlikely. The peccaries on both Fragment A and the Yucatán vase have a curious nasal exhalation in common. However, the Kin sign is tattooed to the peccary's back in the Yucatán vase. Also, resting upon the peccary's back in the Yucatán vase is an undulating Cosmic Serpent that is swallowing a round object. All this imagery seems to explicitly represent a solar eclipse, and supports the interpretation of an eclipse for the Kin marked peccary on Fragment A. In fact, between the years 600 and $900 \mathrm{AD}$ there were six total eclipses across, or near, the Mayan cultural zone; annular eclipses were discounted because the exposure of even a thin ring of the photosphere completely destroys the visual impact of totality. These six eclipses occurred on July 16, 790 (approximate latitude of Mexico City), Aug 26, 797 (approx. lat. of Mazatlán), May 25, 830 (approx. lat. of Hermosillo, Mex.), Sept. 28, 851 (across the Yucatán), May 16, 877 (approx. lat. of Nicaragua), and July 26, 884 (approx. lat. of Mexico City). Any of these events could have potentially been the inspiration for the Yucatán vase. But, it should also be noted that between the years 579 to 826 not a single naked-eye sunspot was recorded in Asia [1]. Although, atmospheric C-14 measurements indicate that a solar sunspot maximum should have occurred near year $700 \mathrm{AD}$ [45]. If the Mayan art sunspot theory is correct, the absence of facial spots on the Yucatán vase chimera would imply that this piece of art was inspired by the eclipse events of 790 or 797 $\mathrm{AD}$, a time of the quiet Sun. Of these two years, only the eclipse of 790, which occurred at 12:56 PM LT at $18.0^{\circ} \mathrm{N}$. Lat. and $102.3667^{\circ} \mathrm{W}$. Long., would have put Gemini in a region of the sky well placed for observation [42]. A creation date at the very end of the $8^{\text {th }}$ century seems plausible, does not contradict artistic evaluation, and is consistent with all the isotopic, geographical and astronomical facts.

It is also interesting to note that by $790 \mathrm{AD}$ most of the Mayan city states were in decline either from incessant warfare or depletion of natural resources via overpopulation. Tonia, Piedras Negras, and Naranjo with its minor close neighbor Río Azul, are exceptions to this trend. Given that the Yucatán vase depicts Tayassu ailbirostris, it seems unlikely that the vase originated from either Tonina or Piedras Negras, since both of these city states lie at the edge of this animal's current known range. The Naranjo region is a more reasonable provenance, especially since this locality 
was known for its exceptional ceramics [46]. The similar imagery on Fragment A and the Yucatán vase is certainly understandable if both originated in the same general area, even if the two pieces are separated by 340 years in time.

There are several possible variations of this basic iconographic interpretation. The king of the Mayan pantheon, Itzamna, is sometimes shown riding a peccary. So, the eclipses of 450 and $790 \mathrm{AD}$ may have been interpreted as a union of the Sun God with Itzamna as he rides his celestial vehicle (the peccary) across the sky [47]. Also, among the Huichol people, who live near Mexico City, the peccary was the Earth God [47]. In this interpretation, the eclipse of 450 $\mathrm{AD}$ would symbolize the union of the sky, represented by the Sun, and the Earth, represented by the peccary. In fact, the mythology of the union of Father Sky and Mother Earth is still alive today among the Navajo people of the southwestern United States [48].

In all these interpretations, a union is brought about that results in a Sun God - Peccary chimera that seem to reference a datable solar eclipse events. And, most importantly for these reports, the chimeras have no facial spots. This fact may be an indication of low solar activity around 450 and $790 \mathrm{AD}$. If the chimera does not refer to a specific solar eclipse but to a general summertime union of the Sun God with the peccary, then the absence of facial spots on the chimera may refer to the quiet Sun of 400 to 460 $\mathrm{AD}$ and the broad period surrounding $790 \mathrm{AD}$. In either interpretation, Fragment A at Río Azul fills the same role as Stela 1 at Tikal. However, it must always be remembered that interpretation of art is difficult, often problematic, and subject to reinterpretations. For example, although there is clear evidence supporting the identification of the peccary with Gemini from Bonampak and numerous pottery specimens [49], there are a few exceptional artifacts showing the identification of the Mayan constellation of the Turtle with Gemini and the Peccary with Orion. It has been suggested by F. Lounsbury that this occasional role reversal might have come about because the similar words áak and $a a k$ in Yucatec mean turtle and pig respectively [49,50]. In either case, both Gemini and Orion would still have both been visible during the eclipses of 450 and $790 \mathrm{AD}$. Therefore, nothing has changed other than the exact celestial location of the peccary. However, in the final analysis, it may very well be that sunspots were not recorded on a chimera, regardless of the condition of the Sun. Although, that scenario seems unlikely judging from other solar animal deities possessing the triplet of spots and dated to active Sun periods [46]. When all this information is taken together, fragment A and the Yucatán vase suggest quiet Sun behavior for the mid-5th century and at the end of the 8th century. This result is consistent with both observations from Asia and physical indicators, supporting an "if-and-only-if" relationship between the appearance and disappearance of the spotted Sun God in Mayan iconography and the actual physical condition of the Sun.

\section{Asian Observations}

As previously discussed in paper IV of this series [37], Governor X's grandfather (Curl Snout) and father (Stormy Sky) both ascended the throne, reigned, and died during a period of exceptional solar activity. Naked-eye sunspot events were recorded for the years 369, 370, 373 (two events), 375, 388, 389, 395, $400 \mathrm{AD}$ [1]. All of these observations were made by Chin-shu, chih in China [1]. Therefore, it is not surprising to find a spotted Sun God heading the list of ancestors. However, between December 6, 400 and July 4, 499 AD, there was not a single Sun spot report from Asia. As discussed in paper IV [37], it has been thought that the lack of observations reflected a lack of interest in Asia [1]. However, fragment A from Río Azul and Stela 1 from Tikal [37] both suggest that the lack of naked-eye sunspot records for the $5^{\text {th }}$ century was not an omission, but a reflection of low solar activity.

The situation is more complex for the time interval from 579 to $826 \mathrm{AD}$. As will be discussed below, a rise in atmospheric carbon-14 levels leaves little doubt that the time interval around $800 \mathrm{AD}$ was a time of the quiet Sun. A fact consistent with the absence of facial spots on the Yucatán vase chimera discussed above. However, the years proximal to $700 \mathrm{AD}$ show low atmospheric $\mathrm{C}-14$ production [45]. This implies an active Sun. The Asian naked-eye sunspot records seem incomplete around $700 \mathrm{AD}$.

\section{Isotopic Measurements (Oxygen-18)}

The climate of the northern hemisphere is strongly influenced by, and coupled to, the sunspot cycle $[33,51]$. During sunspot minima, the Sun's radiant output may be a few tenths of a percent below normal. Although this decrease might not sound like much, it is enough to allow the climate of Europe, and the northern hemisphere in general, to undergo a cooling trend. In fact, it can be cold enough to cause the snow that falls on Greenland (later to become ice at depth as centuries pass) to be depleted in heavy oxygen-18 water. This "heavy water" fraction precipitates out of the air mass preemptively at lower latitudes as high altitude moist air moves northward during its normal atmospheric circulation in the northern hemisphere. The large negative value (a local minimum) of the oxygen- 18 anomaly from Greenland ice cores (-29.2 parts per thousand, denoted by \%o) around $450 \mathrm{AD}[33,52]$ is indicative of a quiet Sun induced cooling trend. During sunspot maxima, the oxygen-18 depletion becomes less negative as the climate of the northern hemisphere, and Greenland, warms. In $369 \mathrm{AD}$, the year in which a series of five naked-eye sunspots began, the oxygen-18 anomaly had a value of $-28.5 \%$. The sunspot series ended in $375 \mathrm{AD}$, just 4 years before Curl Snout (grandfather of Governor X) ascended the throne. A second series of four naked-eye sunspots that began in 388 ended in 400, again 4 years before Curl Snout's death. When this last series had finished, a period of the quiet Sun began. The 
O-18 anomaly dropped to about $-29.1 \%$, and the atmospheric C-14 anomaly began to rise again in good coordination. Similarly, the O-18 anomaly for the quiet Sun year $790 \mathrm{AD}$ was well below the peak value of -28.0 that it would achieve 200 years later during the Medieval Warm.

\section{Isotopic Measurements (Carbon-14)}

Figure 7 shows the $\mathrm{C}-14$ anomaly as a function of time for the first millennium of the common era. The drop in the fractionation corrected radiocarbon anomaly versus time curve in the $369-400 \mathrm{AD}$ time interval is consistent with an active Sun, while the peak at $450 \mathrm{AD}$ is consistent with a quiet Sun. An active Sun ejects a large number of solar wind particles (electrons, protons, alpha particles, and singly charged helium ions) that can change the magnetic properties of the solar wind and the Earth's geomagnetic field. As magnetic shielding properties increase during an active Sun $[53,54,55]$, nitrogen rich lower layers of the atmosphere are partially screened from high energy cosmic rays that are indirectly capable of transmuting naturally occurring nitrogen-14 (99.63\% of all $\mathrm{N})$ into carbon-14 via nuclear reactions. The reverse is, of course, true when the Sun is in a quiet phase (i.e. the atmospheric C-14 level increases). Atmospheric C-14 finds its way into carbon dioxide and is eventually used by trees during photosynthesis. Each tree ring contains the carbon from the year in which it was formed. So, a chronology can be formed that relates atmospheric C-14 levels to a Gregorian date after correcting for radioactive decay. However, the atmosphere has a large reservoir of carbon that changes slowly with time. Observed atmospheric C-14 levels typically lag events on the Sun by about 50 years. Although, this delay might vary based on the intensity and duration of solar conditions, the instantaneous size of the Earth's C-14 reservoir, and the amount of mixing in the atmosphere. It is clear from figure 7 that atmospheric $\mathrm{C}-14$ was on the rise in 800 AD. In fact, solar activity had probably already bottomed out at this time, as evidenced by the peak in the C-14 anomaly 50 years later, and as expected from the imagery on the Yucatán vase. However, the lack of Asian sunspot observations around 700 $\mathrm{AD}$ is in conflict with atmospheric C-14 levels and suggests a gap in the Asian record unrelated to physics.

\section{Tree Rings, Tree Populations and Climate}

During periods of the active Sun (high sunspot activity), the radiant solar output increases by a few tenths of a percent. This extra energy causes the Earth to undergo a warming trend that manifests itself in increased tree ring spacing (increased width of growth rings). At Methuselah Walk in California, some specimens of Pinus Longaeva (the Rocky Mountain Bristle Cone pine) [56] are 8000 years old, making them suitable for climate studies during Early Classic Mayan times. However, in this case, there is little to be learned from these tree rings. It appears that a series of devastating forest fires disrupted the usual patterns of growth. Tragically, these fires occurred in the years 442 and 449 AD, a decade of interest for this report. However, there is data on Oak tree populations from sub-fossil trees buried in fluvial deposits (gravel pits) of large central European rivers (Main, Lahn, Danube, Rhine, Spree, and the Elster) [57]. The individual trees have an average age of only 176 years, with the very oldest specimen reaching 575 years old. In spite of this, the specimens can be sequenced in time because of overlap of their characteristic ring patterns. In Europe, cold and dry conditions often occur together [58], and both are injurious to small soft shoots which would disappear from the sub-fossil record by decay. Given the mean lifespan of the sub-fossil specimens, it probably takes about one or two hundred years for sapling destruction to manifest itself as a decline in mature hard-wood tree populations.

Starting from the more recent records of interest, oak tree populations in central Europe seem to have been devastated around $900 \mathrm{AD}$ on all six rivers above. This may reflect a cold climate circa 800 AD. A cold dry climate implies a quiet Sun, in agreement with the iconography on the Yucatán vase (ca. 790 AD) [51]. Moving backward in time to tree populations in the year $500 \mathrm{AD}$, a count close to a maximum seem to have reached on all rivers. This may reflect the improved growing conditions of the $4^{\text {th }}$ century when solar activity was high, the Earth was warmer, and many juvenile trees probably survived to maturity. By $600 \mathrm{AD}$ tree populations were beginning to decline, most noticeably on the Danube. This may be a reflection of the declining growing conditions of the $5^{\text {th }}$ century. So, in a general way, tree populations agree with Asian records, O-18 measurements, C-14 measurements, and the iconography found on artifacts from Río Azul.

Clearly, tree populations alone are not a definitive indicator of solar induced climate change. Tree populations can be affected by fire, disease, insect infestations, human activity, and changes in the course of a river. Nevertheless, when averaged over several areas (in this case 6 river valleys) they do provide one more clue when taken together with other physical data.

\section{Conclusions}

This publication on Río Azul, and the previous publication of this series on Stela 31 [37], is companion publications in the sense that they cover an identical period of time. However, the solar records were created in two different city-states, providing a, so far, unique opportunity for correlation. In both city-states the period of high solar activity, as evidenced by naked eye Asian sunspot observations and data from isotopes and tree populations, was recorded in the $369-400 \mathrm{AD}$ time fame. Therefore, the spotted Sun God is not just a style associated with one locality. Furthermore, the period of low solar activity 
(400-499 AD) also seems to be reflected in the art at both locations (Stela 1 at Tikal and Fragment A at Río Azul). This suggests that the lack of Asian sunspot records for the $5^{\text {th }}$ century was due to a real decline in sunspots, and not just a decline in interest. The large gap in Asian sunspot records from 579 to $826 \mathrm{AD}$ is more problematic. The Yucatán vase seems to justify a lack of sunspot activity around $800 \mathrm{AD}$, as do C-14 measurements. However, as mentioned above, the Asian sunspot record seems incomplete around $700 \mathrm{AD}$ and is in conflict with C-14 measurements. This apparent paradox will be resolved when the findings from Naj Tunich Cave are presented. These results have important implications for empirical models of the sunspot cycle over century time scales.

The ideas presented in this series of papers may also have useful implications for archeology. For example, the ceramic container found under the west stairway of structure 5D-46 at the level of court 6 of the Central Acropolis at Tikal, was formerly assigned to the Early Classic period by W.R. Coe [59]. If the Mayan art sunspot theory is correct, the container can now be assigned more specifically to the $4^{\text {th }}$ century, and probably the peak solar activity years from 369 to $400 \mathrm{AD}$, because of the spotted Sun God on the side of the container.

Finally, there is a curiosity that deserves comment. The notion of a sunspot as an observable phenomenon was very strong in the Far East. Traveling west the habit of sunspot observation seems to have waned until it became nonexistent in Western Europe during historical times up until the invention of the telescope. Continuing around the globe to the Western Hemisphere the spotted Sun God appears, and brings to mind the myth of the leprosy infected Sun of southern India. Still more remarkable is the similarity of the Aztec Sun God having "dirty marks" on his face with the African Sun God having "mud" on his face. With respect to astronomical traditions, Aveni has pointed out that there are some "remarkably similar conceptualizations between the hemispheres east and west" [60]. It is, perhaps, the commonality of the human experience that causes such mythological "coincidences". Or, perhaps some notion of an imperfect Sun was carried by human migrants across the northern land bridge that once linked Asia to the Americas; since myths may persist for thousands, or even tens of thousands, of years. It is an interesting speculation.

\section{REFERENCES}

[1] Clark D, Stephenson FR. An Interpretation of the Pre-Telescopic Sunspot Records from the Orient. Q. J1. R. Astr. Soc. 1978 Dec; 19: 387-410.

[2] C. Ruggles, Ancient Astronomy: An Encyclopedia of Cosmologies and Myth, 2005, ABC Clio

[3] H. Thurston, Early Astronomy. New York (NY): Springer-Verlag; 1994. 268p.

[4] Kõiva M, Pustylnik I, Vesik L editors. Cosmic Catastrophies,
Proceedings of the SEAC 2002. Tartu (Estonia): Esti Kultuurkapital; 2005. 214p.

[5] Chamberlain VD, Carlson JB, Young MJ, Ruggles C editors. Songs from the Sky. W Sussex (UK): Ocarina Books; 2005, $379 \mathrm{p}$.

[6] Malville JM, Swaninathan RN. Surya Puja Temples of South India. Archaeoastronomy 1996 Jan: 12: 310-19. Also see $p$ 315 of reference 5 .

[7] Robinson A. The Story of Writing: Alphabets, Hieroglyphs \& Pictograms. London (UK): Thames \& Hudson; 1995. p. 145, 175.

[8] Vaquero JM. The Sun Recorded Through History: Astrophysics and Space Science Library, Vol. 361. Dordecht (Germany): Springer; 2009. P. 57-101.

[9] Sayce AH. Babylonian Literature. London (UK): S. Bagster and Sons; 1877. 86p.

[10] Coyne GV. Sunspots: The Historical Background. In: Sonett CP, Giampapa MS, Matthews MS, editors. The sun in time. Tucson: Univ. of Arizona Press; 1991. p. 3-10.

[11] Kondrashov D, Feliks Y, Ghil M. Oscillatory Modes of Extended Nile River Records (A.D. 622-1922). Geophy. Res. Let. 2005 May; 32(10): p. L10702.

[12] Zito RR. Possible Mesoamerican Naked-Eye Observation of Sunspots-II: Evidence from the Codices. In: Rappengluck MA, Rappengluck B, Campion N, Silva F, editors, Astronomy and Power: How Worlds Are Structured, Proceedings of the SEAC 2010 Conference. Oxford (UK): BAR 2794; 2016. P. 205-9.

[13] Seidel M. The Valley of the Kings. In: Schulz R, Seidel M, editors. Egypt: The World of the Pharaohs. New York (NY): Konemann; 2002. p.226.

[14] Belmonte JA, Shaltout M, and Fekri M. Astronomy, Landscape, and Symbolism: A Study of the Orientation of Ancient Egyptian Temples. In: Belmonte JA and Shaltout M, editors. In Search of Cosmic Order: Selected Essays on Egyptian Archaeoastronomy. Cairo (Egypt): Supreme Council of Antiquities Press; 2009. p. 215-83.

[15] King D. The Orientation of Medieval Islamic Religious Architecture and Cities. J. for the History of Astron. 1995 Aug; 26(3): p. 253.

[16] King D, Gingerich O. Some Astronomical Observations from Thirteenth-Century Egypt. J. for the History of Astron. 1982 June; 13(2): p. 121.

[17] Nasr SH. Islamic Science: An Illustrated Study. London(UK): World of Islam Festival Publishing Co.; 1976. p. 98.

[18] King DA. Islamic Astronomy. In: Walker C, editor. Astronomy Before the Telescope. London (UK): British Museum Press; 1996. P.143-74.

[19] Bahn PG. Cave Art: A Guide to the Decorated Ice Age Caves of Europe. London (UK): Frances Lincoln LTD; 2007. 248 p.

[20] A.P. Norton, Norton's Star Atlas, Sky Publishing, Cambridge Mass., 1973. P. 6, 11,91,92.

[21] Bekbassar NM. Ancient Constellations of Central Asia. In: Astronomy: Mother of Civilization and Guide to the Future," Programme: XXI SEAC Conference, Athens (Greece) Sept. 


$$
\text { 1-7, 2013, p. 17-18. }
$$

[22] Hoskin M. Tombs, Temples, and their Orientations: A New Perspective on Mediterranean Prehistory. W Sussex (UK): Ocarina Books; 2001, 264p.

[23] Anon. Dólmenes de Antequera. Conjunto Arqueológico, Ctra. De Málaga 5, 29200 Antequera (Málaga), Tel. 9527122 06/07, wwwjuntadeandalucia.es/cultura.

[24] McCutcheon RA. Book Review (in English) on "Astronomy of Ancient Russia" (in Russian). J. for the History of Astron. 2008 Aug; 39(3): 412-4.

[25] Svyatskiy D and Gorodetskiy ML. Astronomiya drevnei Rusi. Moscow: Russkaya Panorama; 2007. 663p.

[26] Solheim JE. The Northern Light as Messenger from the Other World and Harbinger of War and Disaster. In: Kõiva M, Pustylnik I, Vesik L editors. Cosmic Catastrophes, Proceedings of the SEAC 2002. Tartu (Estonia): Esti Kultuurkapital; 2005. P. 167-74.

[27] Healy JF. Pliny the Elder- Natural History: A Selection. London (UK): Penguin Books; 1991. p. 22, 28.

[28] Galindo Trejo J and Allen C. Maya observations of $13^{\text {th }}$ century transits of Venus? In: Kurtz DW, editor. IAU Colloq. 196: Transits of Venus: New Views of the Solar System and Galaxy. Cambridge (UK): Cambridge U. press; 2005. p. 124-37.

[29] Brody J. The Enigma of Sunspot: A Story of Discovery and Scientific Revolution. Edinburgh (UK): Floris Books; 2002. $191 \mathrm{p}$.

[30] Schuster AMH. Epi-Olmec Decipherment. 1997 July. www.archaeology.org/online/news/la.mojarra.html. Accessed Oct. 3, 2016.

[31] Amber JR. The Anasazi: Prehistoric People of the Four Corners Region. Flagstaff (AZ): Museum of Northern Arizona, 1977. p. 6, 25.

[32] Fialko VC. El marcador de juego de pelota de Tikal: nuevas referencias epigráficas para el period clásico temprano. Mesoamérica 1988 June; 15: 117-35.

[33] Zito RR. Possible Mesoamerican Naked-Eye Observation of Sunspots - III: Evidence from the Hauberg Stela. In: Šprajc I, Pehani P (editors). Ancient Cosmologies and Modern Prophets, Anthropological Notebooks, Year XIX Supplement. Ljubljana (Slovene): Slovene Anthropological Society; 2013. P. 339-46.

[34] Milbrath S. Star Gods of the Maya: Astronomy in Art, Folklore, and Calendars. Austin (TX): U. of Texas Press; 1999. p. 58-104.

[35] Aveni AF. Skywatchers. Austin (TX): U. of Texas Press; 2001. 410p.

[36] Zito RR. Possible Mesoamerican Naked-Eye Observation of Sunspots-I: Evidence from the Tikal Ball Court Marker. In: Rappengluck MA, Rappengluck B, Campion N, Silva F, editors, Astronomy and Power: How Worlds Are Structured, Proceedings of the SEAC 2010 Conference. Oxford (UK): BAR 2794; 2016. P. 193-6.

[37] Zito RR. Possible Mesoamerican Naked-Eye Observation of Sunspots - IV: Evidence from Tikal Stela 31. In: Šprajc I, Pehani P (editors). Ancient Cosmologies and Modern
Prophets, Anthropological Notebooks, Year XIX Supplement. Ljubljana (Slovene): Slovene Anthropological Society; 2013. P. 347-55.

[38] Adams REW. Río Azul: An ancient Maya city. Norman OK: U. of Oklahoma Press; 1999. 238 p.

[39] Grzimek B. Grzimek's animal life encyclopedia; vol. 13. New York: Van Nostrand; 1972. pp. 90-108.

[40] Anon., NASA Solar Eclipse Page, eclipse.gsfc.nasa.gov/solar .html, accessed Sept. 21, 2016.

[41] Hirshfeld A. Sinnott RW. Sky catalogue 2000.0; vol. 1, stars to magnitude 8.0, Cambridge, Mass.: Sky Publishing Corp.: 1982. p. 186-92.

[42] Anon., Starry Night Enthusiast program, Version 6, Simulation Curriculum Corp., www,StarryNight.com, 2010.

[43] Coe MD 1973. The Maya scribe and his world, New York: Grolier Club: 1973. p. 126.

[44] Freidel D, Schele L, Parker J. Maya cosmos: three thousand years on the shaman's path. New York: Morrow and Company; 1993. p. 80-7.

[45] Damon P, Sonett CP. 1991. Solar and terrestrial components of the atmospheric ${ }^{14} \mathrm{C}$ variation spectrum. In: Sonett $\mathrm{CP}$, Giampapa MS, Matthews MS, editors. The sun in time. Tucson: Univ. of Arizona Press; 1991. p. 360-88.

[46] Martin S, Grube N. Chronicle of the Maya kings and queens, London: Thames and Hudson; 2000. p. 22, 23, 69, 94, 142.

[47] Miller M, Taube K. An illustrated dictionary of the gods and symbols of ancient Mexico and the Maya. London: Thames \& Hudson; 1993. pp. 99-100, 132-3.

[48] Griffin-Pierce, T. Earth is my mother, sky is my father. Albuquerque: U. of NM; 1992. plate 4.

[49] Freidel D, Schele L, Parker J. Maya cosmos: three thousand years on the shaman's path. New York: Morrow and Company: 1993. p. 80-7.

[50] Montgomery J. Maya (Yucatec) dictionary and phrasebook, New York: Hippocrene Books; 2004. p. 49, 118.

[51] Eddy JA. The Case of the Missing Sunspots. Scientific American. 1977 May; 236(5): 80-92.

[52] Dansgaard W, Johnsen SJ, Møller, J Langway Jr. CC. One Thousand Centuries of Climate Record from Camp Century on the Greenland Ice Sheet. Science, New Series, 1969 Oct; 166 (3903): 377-381.

[53] Stuiver M, Quay PD. Changes in atmospheric carbon-14 attributed to a variable sun. Science. 1980 Jan; 207 (4426): $11-9$.

[54] Bard E, Raisbeck GM, Yiou F, Jouzel J. Solar modulation of cosmogenic nuclide production over the last millennium: comparison between ${ }^{14} \mathrm{C}$ and ${ }^{10} \mathrm{Be}$ records. Earth and Planetary Science Letters. 1997 Aug; 150: 453-62.

[55] Beer, J. Long-term indirect indices of solar variability. Space Science Reviews. 2000 Nov; 94: 53-66.

[56] D.A. Graybill, Tree Ring Data Bank (www.ncdc.noaa.gov/paleo/treering.html), NOAA, 2009. 
[57] Friedrich M, Remmele S, Kromer B, Hofmann J, Spurk M, Kaiser KF, Orcel C, Küppers M. 2004. The 12,460 - year Hohenheim oak and pine tree-ring chronology from Central Europe - a unique annual record for radiocarbon calibration and paleoenvironment reconstructions. Radiocarbon. 2004; 46 (3): 1111-22.
[58] Cunliffe B. Europe between the oceans. New Haven, CT: Yale U. Press; 2008. p. 62-3.

[59] Coe WR. Tikal. Philadelphia: Univ. of Pennsylvania; 1967. p. 69-70.

[60] Aveni AF. Astronomy in the Americas. In: Walker C, editor. Astronomy Before the Telescope. London (UK): British Museum Press; 1996. p. 269-303. 